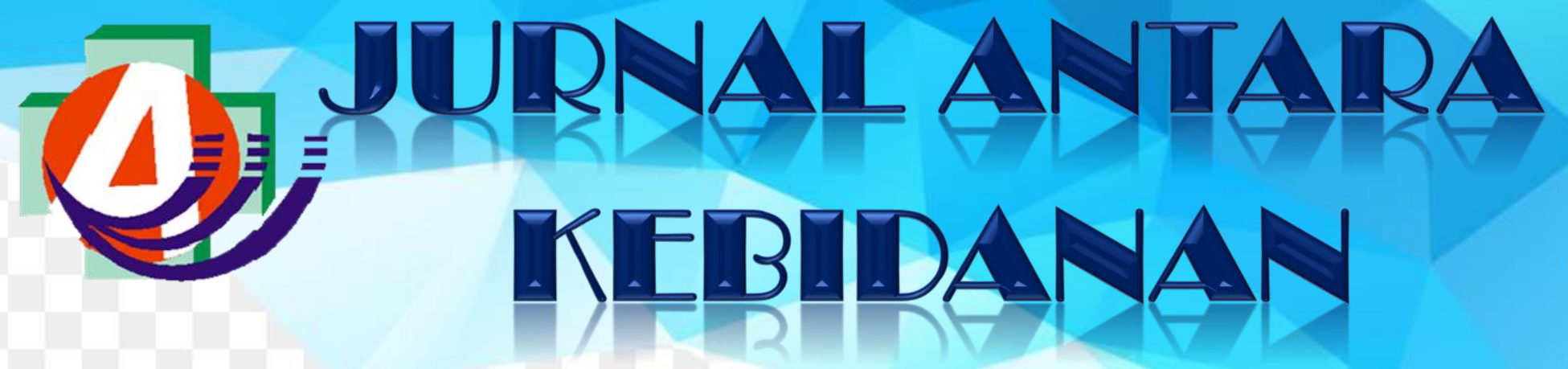

1. Faktor-Faktor Yang Berhubungan Dengan Kematian Bayi Berat Lahir Rendah Di RSUD Labuang Baji Makassar (Daswati, Nurbiah Eka Susanty)

2. Hubungan Dukungan Suami Dan Usia Ibu Hamil Dengan Kunjungan Antenatal Careldeal Di Puskesmas Mamboro Palu (Erni)

3. Dampak Berat Badan Lahir Rendah Terhadap Kehamilan Yang Tidak Diinginkan (Feva Tridiyawati, Mariyani, Resi Galaupa)

4. Pengetahuan Remaja Tentang Infeksi Menular Seksuak Di SMK Jaya Cimuning Bekasi Tahun 2020

(Tuty Yanuarti,Novita, Lia Idealistiana)

5. Keterlibatan Orangtua Terhadap Pendidikan Anak Usia Dini (Mariyani, Ita Herawati, Rahayu Khairiah)

6. Pengaruh Ibu Hamil Trimester I Dalam Upaya Penanganan Mual Muntah (Rahayu Khairiah,Feva Tridiyawati, Tuty Yanuarti)

7. Pengaruh Responsiveness Dan Assurance Perawat Terhadap Kepuasan Pasien Di Ruang Instalasi Gawat Darurat RSU UKI (Maryati Sutarno, Natalina Panjaitan)

8. Hubungan Pengetahuan Ibu Tentang Imunisasi Booster Dengan Imunisasi Dasar Lengkap Di Wilayah Kerja Puskesmas Bojong Rawa Lumbu (Nur Sitiyaroh, Siarny Dormy Manalu, Nurlaela)

9. Faktor-Faktor Yang Berhubungan Dengan Perilaku Higienis Saat Menstruasi (Lucy Amelia, Nadra Sylvia F)

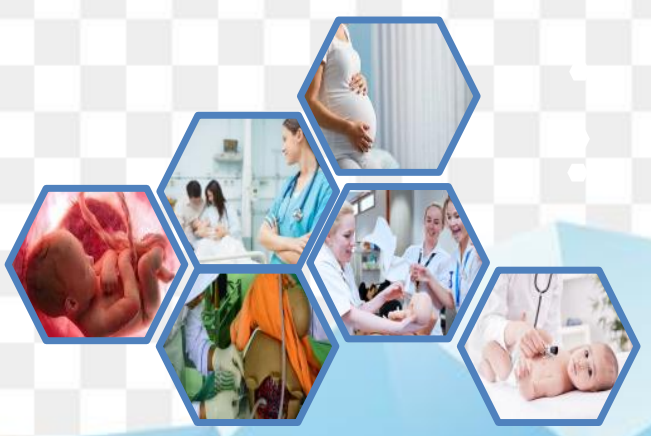

Volume 4 Nomer 1 


\title{
Faktor-Faktor Yang Berhubungan Dengan Kematian Bayi Berat Lahir Rendah Di RSUD Labuang Baji Makassar
}

\section{Related Factors To Mortality Of Low Birth Weight Babies In Regional Public Hospital Labuang Baji Makassar}

\author{
Daswati ${ }^{1}$, Nurbiah Eka Susanty ${ }^{2}$ \\ 1,2 AKBID Muhammadiyah Makassar \\ Email : Daswa.amin@yahoo.co.id
}

\begin{abstract}
ABSTRAK
Bayi Berat Lahir Rendah (BBLR didefenisikan sebagai neonatus yang lahir terlalu kecil yaitu bayi yang lahir dengan berat badan antara 500- $<2500$ gr. Untuk mengetahui faktor-faktor yang berhubungan dengan kematian bayi berat lahir rendah di RSUD Labuang Baji Makassar. Metode penelitian ini menggunakan observasi analitik dengan pendekatan cross sectional study. Populasi dalam penelitian ini adalah semua bayi berat lahir rendah (BBLR) yang dirawat di RSUD Labuang Baji Makassar tahun 2013-2015. Sampel dalam penelitian ini adalah semua bayi berat lahir rendah yang meninggal di RSUD Labuang Baji Makassar tahun 2013-2015. Teknik pengambilan sampel purposive sampling. Ada hubungan yang signifikan antara asfiksia, infeksi/sepsis, hipoglikemia, hiperbilirubinemia, hipotermia, Respiratory Distress Syndrom (RDS) terhadap kejadian kematian BBLR. Perlunya upaya deteksi dini komplikasi yang mungkin terjadi pada bayi dengan BBLR. Penanganan yang tepat dan cepat, termasuk sistem rujukan bayi dengan BBLR.
\end{abstract}

\section{ABSTRACT}

Low Birth Weight (LBW is defined as a neonate born too small, a baby born with a weight between 500$<2500$ grams. To find out factors related to mortality of low birth weight babies at Labuang Baji Regional General Hospital of Makassar. This research method uses analytic observation with cross sectional study approach. The population in this study were all low birth weight infants (BBLR) treated at the Regional General Hospital of Labuang Baji Makassar in 2013-2015. The sample in this study were all low birth weight babies who died at the Regional General Hospital of Labuang Baji Makassar in 2013-2015. Sampling technique purposive sampling. There is a significant association between asphyxia, infection/ sepsis, hypoglycemia, hyperbilirubinemia, hypothermia, Respiratory Distress Syndrome (RDS) on the occurrence of LBW death. The need for early detection of complications that may occur in infants with LBW. Appropriate and fast handling, including referral systems for babies with LBW

\section{PENDAHULUAN}

Indonesia sebagai salah satu negara berkembang, berdasarkan Survei Demografi dan Kesehatan Indonesia (SDKI) pada tahun 2007, angka kematian neonatal sebesar 19 per 1.000 kelahiran hidup. Dalam 1 tahun, sekitar 86.000 bayi usia 1 bulan meninggal. Artinya setiap 6 menit ada 1 (satu) neonatus meninggal (Kemenkes RI, 2011).Sementara laporan WHO yang dikutip dari State of the world's mother 2007 dikemukakan bahwa $27 \%$ kematian neonatal disebabkan oleh Bayi Berat Lahir Rendah (BBLR). BBLR masih merupakan masalah di bidangkesehatan terutama kesehatan perinatal(Depkes RI, 2008).

Menurut Kemenkes RI (2014) bahwa sebanyak 78,5\% kematian neonatal terjadi pada usia 0-6 hari yang sebahagaian besar disebabkan oleh gangguan pernafasan (35\%), infeksi/sepsis (12\%), prematuritas termasuk BBLR (32\%). Selain itu, BBLR juga rentan terhadap hipotermi dan infeksi yang merupakan penyebab kematian langsung pada neonatus. BBLR secara khusus merupakan indikator penting kesehatan reproduksi. BBLR dianggap sebagai prediktor yang paling penting dari penyebab kematian bayi, khususnya kematian yang terjadi pada bulan pertama 
kelahiran. Hal ini masih menjadi masalah kesehatan masyarakat di seluruh dunia terutama di negara-negara berkembang (Deshpande Jayant D. dkk, 2011).

Menurut Riset Kesehatan Dasar (Riskesdas) tahun 2010, angka kejadian BBLR di Indonesia adalah $11,1 \%$ dan di Sulawesi Selatan mencapai angka yang lebih tinggi dibanding dengan angka nasional yaitu 16,2\% (Kemenkes, 2010), sementara di RSUD Labuang Baji Makassar sebagai salah satu rumah sakit yang memberikan pelayanan perinatal pada tahun 2011 terdapat bayi lahir dengan prematur sebanyak $10,6 \%$ dan meningkat menjadi 11,5\% pada tahun 2012 (Rekam medik RSUD Labuang Baji Makassar).

Menurut Agustin CA (2007) BBLR merupakan faktor determinan utama terhadap kesakitan dan kematian bayi dan secara umum kejadian BBLR disebabkan oleh multi faktor. Menurut Saifudin AB (2009)bayi berat lahir rendah potensial mengalami berbagai komplikasi seperti asfikisa, hipotermi, hipoglikemia, masalah dalam pemberian ASI, ikterus dan hiperbilirubinemia.

Asfiksia merupakan penyebab kematian bayi yang paling tinggi yaitu sekitar $27 \%$ dan kematian bayi karena asfiksia mencapai $41,94 \%$ terjadi di RS Pusat rujukan provinsi. Penelitan di Sagamu, Nigeria juga melaporkan bahwa kematian bayi dengan berat badan lahir rendah $(<1500 \mathrm{gr})$ berhubungan dengan kejadian asfiksia (Ogunlesi, 2011). Menurut I Ketut Duara (2015) bahwa BBLR yang mengalami asfiksia akan mengakibatkan hipoksia jaringan yang akan meningkatkan risiko kematian.

Menurut Kosim S dkk. (2012), hiperbilubinemia meningkat pada bayi yang lahir dengan BBLR kurang bulan.
Pada kebanyakan bayi baru lahir, hiperbilirubinemia tak terkonjugasi merupakan fenomena transisional yang normal. Tetapi beberapa bayi, terjadi peningkatan bilirubin secara berlebihan sehingga bilirubin berpotensi menjadi toksikyang dapat menyebabkan kematian bayi, dan bila bayi tersebut dapat bertahan hidup pada jangka panjang akan menimbulkan sekuele nerologi.

Sedangkan sepsis merupakan keadaan penyakit sistemik yang disebabkan oleh invasi mikroba pada bagian tubuh yang biasanya steril. Kejadian sepsis ini meningkat pada bayi yang lahir kurang bulan dan BBLR. Di Rumah Sakit Cipto Mangunkusumo kejadian sepsis ini mencapai $13,7 \%$ dan kasus kematian mencapai 14\% (Kosim S dkk, 2012).

Terkait dengan hal tersebut, maka dibutuhkan suatu upaya yang dapat menurunkan kejadian kematian BBLR dengan mengenal beberapa faktor terkait dengan kematian BBLR, sehingga dapat diberi penanganan secara cepat dan tepat yang pada akhirnya kesakitan dan kematian akibat kelahiran BBLR dapat berkurang secara nyata.

\section{METODE PENELITIAN}

Jenis penelitian yang digunakan adalah observasi analitik dengan pendekatan cross sectional study. Populasi dalam penelitian ini adalah semua bayi berat lahir rendah (BBLR) yang dirawat di RSUD Labuang Baji Makassar tahun 2013-2015. Sampel dalam penelitian ini adalah semua bayi berat lahir rendah yang dinyatakan meninggal di RSUD Labuang Baji Makassar tahun2013-2015. Teknik pengambilan sampel yang digunakan adalah secara purposive sampling yaitu teknik pengambilan sampel yang 
didasarkan pada suatu pertimbangan tertentu.

\section{HASIL PENELITIAN}

Tabel 1.

Distribusi Bayi Berat Lahir Rendah

(BBLR) yang Meninggal di RSUD

Labuang Baji Tahun 2013-2015

\begin{tabular}{lcc}
\hline \multirow{2}{*}{ BBLR } & \multicolumn{2}{c}{ Jumlah } \\
\cline { 2 - 3 } & $\mathbf{n}$ & $\mathbf{\%}$ \\
\hline Hidup & 89 & 43 \\
Meninggal & 118 & 57 \\
\hline \multicolumn{1}{c}{ Jumlah } & $\mathbf{2 0 7}$ & $\mathbf{1 0 0}$ \\
\hline
\end{tabular}

Sumber : Data primer

Tabel 1. Menunjukkan bahwa Bayi Berat Lahir Rendah (BBLR) yang meninggal di RSUD Labuang Baji Tahun 2013-2015 sebanyak 57\%.

Berat badan merupakan salah satu indikator kesehatan bayi baru lahir. Secara umum, bayi berat lahir rendah, lebih besar risikonya untuk mengalami masalah. Masa gestasi jua merupakan indikasi kesejahteraan bayi baru lahir, karena semakin cukup masa gestasinya semakin baik kesejahteraan bayi baru lahir. Hubungan anatar umur kehamilan dengan berat badan lahir mencerminkan kecukupan pertumbuhan intra uterine.

Penentuan hubungan ini, akan mempermudah antisipasi morbiditas dan mortalitas selanjutnya. Hubungan antara berat lahir dan aatu umur kehamilan juga sangat membantu dalam meramalkan masalah klinis BBL Kosim S dkk (2012).

Bayi yang lahir dengan berat badan sangat rendah, memiliki risiko tinggi mengalami cedera otak dan gangguan perkembangan otak. Meskipun tingkat kelangsungan hidup untuk bayi prematur meningkat dalam dekade terakhir ini karena perawatan yang intensif neonatal yang lebih baik, namun cacat motorik seperti cerebral palsy, penurunan fungsi kognitif, bahasa, perkembangan sosial tidak menurun (Emma dkk 2013).

\section{Hubungan antara kematian BBLR dengan Asfiksia}

Tabel 2.

Distribusi Bayi Berat Lahir Rendah

(BBLR) yang Meninggal dan Mengalami Asfiksia di RSUD Labuang Baji

Tahun 2013-2015

\begin{tabular}{llllllll}
\hline \multirow{2}{*}{ BBLR } & \multicolumn{3}{l}{ Hidup } & Meninggal & Jumlah & \multirow{P}{*}{} \\
\cline { 2 - 6 } & n & $\%$ & N & $\%$ & n & $\%$ & value \\
\hline
\end{tabular}

$\begin{array}{llllll}\text { Asfiksia } & 1921,3 & 63 & 53,4 & 82 & 39,6\end{array}$

Tidak Asfiksia 70 78,7 55 46,6 12560,4 0,000

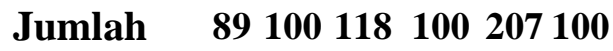

\section{Sumber : Data primer}

Tabel 2. menunjukkan bahwa dari 89 BBLR yang hidup, 21,3\% mengalami asfiksia dan 78,7\% tidak mengalami asfiksia. Sedangkan BBLR yang meninggal, 53,4\% mengalami asfiksia dan $46,6 \%$ tidak mengalami asfiksia.Hasil analisis chi-square didapatkan nilai $\mathrm{p}=$ 0,000 (signifikan), nilai ini berarti ada pengaruh asfiksia terhadap kematian BBLR.

Kelahiran dengan asfiksia merupakan kondisi yang menyedihkan, karena bayi baru lahir tidak dapat bernafas secara spontan atau bahkan gagal bernafas. Hal ini tentunya akan mengurangi perfusi oksigen ke berbagai organ vital (Hafiz MA dkk, 2014). Menurut Kosim S dkk. (2012), BBL mempunyai karekteristik yang unik. Transisi dari kehidupan janin intra uterine ke kehidupan ekstra uterin, menunjukkan alveoli paru janin dalam uterus berisi cairan paru. Pada saat lahir dan bayi mengambil nafas pertama, udara memasuki alveoli paru dan cairan paru diabsorpsi oleh jaringan paru. Pada nafas kedua dan berikutnya, udara yang masuk 
ke alveoli berisi udara yang mengandung oksigen. Aliran darah paru meningkat secara dramatis. Hal ini disebabkan ekspansi paru yang membutuhkan tekanan puncak inspirasi dan tekanan akhir ekspirasi yang lebih tinggi. Ekspansi paru dan peningkatan tekanan oksigen alveoli, keduanya, menyebabkan penurunan resistensi vaskuler paru dan peningkatan aliran darah paru setelah lahir.

Menurut Kosim S dkk. (2012), aliran darah intrakardial dan ekstrakardial mulai beralih arah yang kemudian diikuti penutupan duktus arteriosus. Kegagalan penurunan resistensi vaskuler paru menyebabkan huipertensi pulmonal persisten pada BBL (Persisten Pulmonary Hypertension og the Naeonate), dengan aliran darah paru yang inadekuat dan hipoksemia relatif. Ekspansi paru yang inadekuat menyebabkan gagal nafas. Asfiksia pada Bayi Baru Lahir (BBL) menjadi penyebab kematian $19 \%$ dari 5 juta kematian BBL setiap tahun. Di Indonesia angka kejadian asfiksia di rumah sakit provinsi Jawa Barat adalah 25,2\%, dan angka kematian karena asfiksia di rumah sakit pusat rujukan provinsi di Indonesia sebesar $41,94 \%$.

BBLR berkontribusi secara substansial terhadap kesakitan dan kematian neonatal (Ravi dkk, 2015). Kematian neonatal menyumbang $40 \%$ kematian anak usia di bawah lima tahun, $75 \%$ diantaranya meninggal pada minggu pertama kelahiran, dan 25\%-45\% meninggal dalam 24 jam pertama kelahiran. Secara umum, kelahiran prematur merupakan penyebab langsung kematian neonatal. Kelahiran preterm dan Kecil Masa Kehamilan (KMK) yang menjadi penyebab terjadinya BBLR. Sedangkan BBLR menyumbang 60\%-80\% kematian neonatal. Secara umum, penyebab utama kematian neonatal adalah infeksi (35\%), kelahiran prematur (28\%) dan asfiksia (23\%). Lain halnya di Afrika, infeksi berkontribusi terhadap kematian neonatal sampai $39 \%$, prematuritas sebanyak 25\% dan asfiksia 24\% (Onesmus MM dkk, 2015).

\section{Hubungan antara kematian BBLR dengan infeksi/sepsis}

Tabel 2.

Distribusi Bayi Berat Lahir Rendah

(BBLR) yang Meninggal dan Mengalami Sepsis di RSUD Labuang Baji

Tahun 2013-2015

\begin{tabular}{cccccccc}
\hline \multirow{2}{*}{ BBLR } & \multicolumn{2}{c}{ Hidup } & Meninggal & Jumlah & \multicolumn{1}{c}{$\boldsymbol{P}$} \\
\cline { 2 - 8 } & $\mathrm{N}$ & $\%$ & $\mathrm{n}$ & $\%$ & $\mathrm{~N}$ & $\%$ & value \\
\hline
\end{tabular}

$\begin{array}{lllllll}\text { Sepsis } & 16 & 18 & 74 & 62,7 & 90 & 43,5\end{array}$ Tidak sepsis $73 \quad 82 \quad 44 \quad 37,3 \quad 117 \quad 56,50,000$

Jumlah $\quad 89100118 \quad 100 \quad 207 \quad 100$

Tabel 2. menunjukkan bahwa dari 89 BBLR yang hidup, $18 \%$ mengalami sepsis dan $82 \%$ tidak mengalami sepsis. Sedangkan BBLR yang meninggal, $62,7 \%$ mengalami sepsis dan $37,3 \%$ tidak mengalami sepsis.Hasil analisis chi-square didapatkan nilai $\mathrm{p}=0,000$ (signifikan), nilai ini berarti ada pengaruh sepsis terhadap kematian BBLR.

Laporan WHO yang dikutip dari Child Health Research Project Special Report dikemukakan bahwa $42 \%$ kematian BBL terjadi karena berbagai bentuk infeksi, seperti infeksi saluran pernafasan, tetanus neonatorum, sepsis dan infeksi gastrointestinal. Di samping tetanus neonatorum, case fatality rate yang tinggi ditemukan pada sepsis neonatal. Hal ini terjadi karena banyak faktor risiko pada 
masa perinatal yang belum dapat dicegah dan ditanggulangi. Sepsis pada BBL adalah infeksi aliran darah yang bersifat invasif ditandai dengan ditemukannya bakteri dalam cairan tubuh seperti darah, cairan sumsum tulang atau air kemih. Keadaan ini sering terjadi pada bayi berisiko, misalnya pada bayi BBLR. Infeksi dapat terjadi secara vertikal karena penyakit ibu atau infeksi yang diderita oleh ibu selama persalinan atau kelahiran. Selain itu, infeksi juga dapat terjadi secara horizontal yang termasuk di dalamnya infeksi karena kuman nasokomial (Kosim S dkk. 2012).

Selama dalam kandungan janin relatif aman terhadap kontaminasi kuman karena terlindung oleh berbagai organ tubuh seperti placenta, selaput amnion, khorion dan beberapa faktor anti infeksi pada cairan amnion. Walaupun demikian kemungkinan kontaminasi kuman dapat timbul melalui berbagai jalan seperti: infeksi kuman, prosedur obstetri yang kurang memperhatikan faktor aseptik/antiseptik, dan pada saat ketuban pecah (Kosim S dkk, 2012).

Christoph PH dkk, 2012, melaporkan bahwa lebih dari 108.000 bayi berat lahir sangat rendah yang dirawat dengan sepsis terjadi lebih dini 1.032 bayi. Hal ini meningkatkan risiko kematian bayi dengan OR 1,45 (95\%, CI 1,21). Bayi dengan berat badan sangat rendah cepat atau lambat memiliki risiko terjadi sepsis. Beberapa penelitian sebelumnya melaporkan bahwa sepsis yang terjadi secara dini disebabkan oleh mikroorganisme gram negatif, sedangkan sepsis yang terjadi setelah beberapa hari perawatan disebabkan oleh organisme gram positif. Sepsis yang terjadi dalam 3 hari pertama kehidupan, biasanya disebabkan oleh organisme yang ditransmisikan secara vertikal dari ibu ke bayi sebelum atau pada saat kelahiran.

Seyyen AA 2016, melaporkan bahwa sepsis neonatal menyebabkan peningkatan angka kematian bayi. Di negara-negara maju, kejadian early onset sepsis adalah 11/1000 pada bayi baru lahir dengan berat badan lahir sangat rendah dan $21 \%$ berkembang menjadi Late Onset Sepsis sebesar246.000 episode per tahun. Angka ini adalah 3 juta per tahun di negara berkembang. Studi tentang kematian neonatal telah dilaporkan bahwa 99\% laporan kematian neonatal berasal dari negara berkembang dan $25 \%$ bayi baru lahir lahir karena infeksi. Bayi berat badan lahir sangat rendah rentan mengalami infeksi serius karena belum memiliki sistem kekebalan tubuh yang belum matang.

\section{Hubungan antara kematian BBLR dengan Hipoglikemia}

Tabel 3.

Distribusi Bayi Berat Lahir Rendah (BBLR) yang Meninggal dan Mengalami Hipoglikemia di RSUD Labuang Baji Tahun 2013-2015

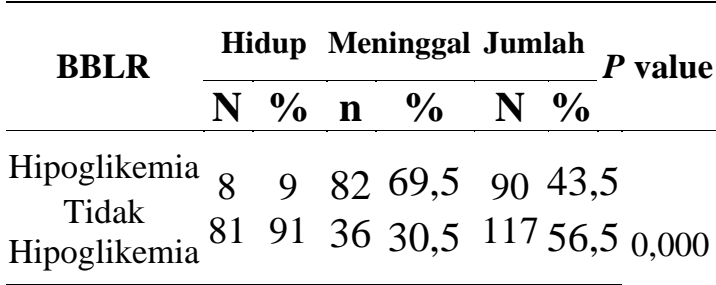

Jumlah $89100118100 \quad 207100$

\section{Sumber : Data Primer}

Tabel 3. menunjukkan bahwa dari 89 BBLR yang hidup, 9\% mengalami hipoglikemia dan 91\% tidak mengalami hipoglikemia. Sedangkan BBLR yang meninggal, $\quad 69,5 \%$ mengalami hipoglikemia dan 30,5\% tidak mengalami hipoglikemia.Hasil analisis chi-square 
didapatkan nilai $\mathrm{p}=0,000$ (signifikan), nilai ini berarti ada pengaruh hipoglikemia terhadap kematian BBLR.

Hipoglikemia adalah keadaan dimana kadar glukosa darah tidak dapat mencukupi kebutuhan tubuh. Bayi yang berisiko tinggi mengalami hipoglikemia diantaranya adalah bayi prematur dengan usia kehamilan kurang dari 37 minggu, bayi kecil untuk masa kehamilan/BBLR. Hipoglikemia berhubungan dengan keluaran neurologis yang jelek. Percobaan pada hewan menunjukkan bahwa kejadian hipoglikemik yang bersamaan dengan hipoksik-iskemik menunjukkan daerah infark yang lebih besar dan menunjukkan angka keselamatan yang lebih rendah. Pada neonatus kadar glukosa darah harus dipertahankan pada kadar 50-110mg/dl 34,25 (Effendi SH, Puspitasari M, 2012).

Mathias K dkk (2013) dalam laporan penelitiannya, menemukan bayi lahir preterm (usia kehamilan <32 minggu) sebanyak 98bayi. Selanjutnya subyek penelitian dianalisis secara statistik, dengan cara subyek penelitian dibagi menjadi dua kelompok yaitu kelompok 1=berat lahir <1000gr, $\mathrm{n}=54$; kelompok 2=berat lahir 1000-1499gr, n=44. Hasil analisis menunjukkan bahwa kelompok 1 mengalami hipoglikemia sebanyak 24 bayi $(1,44 \%)$ dengan glukosa darah $<45 \mathrm{mg} / \mathrm{dl})$ dibandingkan dengan kelompok 2 mengalami hipoglikemia sebanyak $23 \%$ (10 dari 44 bayi).

Penelitian yang dilakukan oleh Abdelwaheb MMD dkk (2010) menunjukkan bahwa sebanyak $26 \%$ bayi lahir dengan kecil masa kehamilan mengalami hipoglikemia yang perlangsungannya terjadi pada 23 jam pertama setelah kelahiran. Kadar gula darah persisten $<2,6 \mathrm{mmol} / \mathrm{L}$ pada bayi prematur atau kecil masa kehamilan, mempunyai potensi mengalami keterlambatan perkembangan sistem persarafan. Telah lama diketahui bahwa bayi dengan berat badan lahir rendah memiliki risiko untuk mengalami hipoglikemia.

Menurut Ali B dkk (2016) bahwa, hipoglikemia sering terjadi pada periode neonatal akan tetapi kondisi ini sebenarnya tidak boleh terjadi, karena hal tersebut dapat menimbulkan komplikasi neurologis dan motorik, namun dapat dicegah dengan asuhan yang tepat.

Ve'dı's HE dkk, 2013 juga melaporkan hasil penelitiannya menunjukkan bahwa pertumbuhan janin terhambat meningkatkan kejadian bayi lahir dengan berat badan rendah, dan hal ini dipicu oleh faktor ekonomi yang rendah. Selain itu, bayi yang lahir dengan berat badan lahir rendah atau prematur secara nyata meningkatkan kejadian kesakitan dan kematian perinatal.

\section{Hubungan antara kematian BBLR dengan Hiperbilirubinemia}

Tabel 4.

Distribusi Bayi Berat Lahir Rendah (BBLR) yang Meninggal dan Mengalami Hiperbilirubinemia di RSUD Labuang Baji Tahun 2013-2015

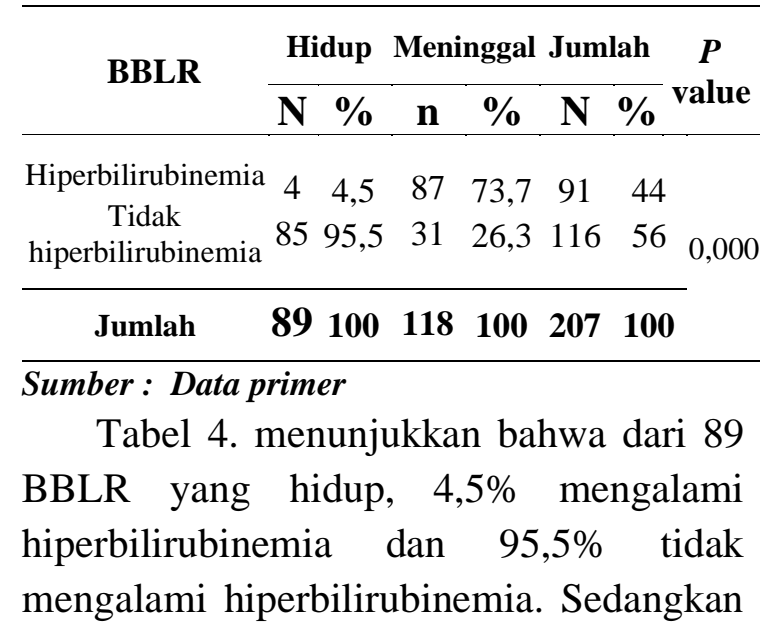


BBLR yang meninggal, 73,7\% mengalami hiperbilirubinemia dan $26,3 \%$ tidak mengalami hiperbilirubinemia. Hasil analisis chi-square didapatkan nilai $\mathrm{p}=$ 0,000 (signifikan), nilai ini berarti ada pengaruh hiperbilirubinemia terhadap kematian BBLR.

Hyperbilirubinemia merupakan salah satu fenomena klinis yang paling sering ditemukan pada bayi baru lahir. Lebih dari $85 \%$ bayi cukup bulan yang kembali dirawat dalam minggu pertama kehidupan yang disebabkan oleh Hyperbilirubinemia. Gejala yang nampak pada kasus ini adalah bayi terlihat berwarna kuning, keadaan ini timbul akibat akumulasi pigmen bilirubin (4Z, $15 \mathrm{Z}$ bilirubin IX alpha) yang berwarna ikterus pada sklera dan kulit. Isomer bilirubin ini berasal dari degradasi heme yang merupakan komponen hemoglobin mamalia. Pada masa transisi setelah lahir, hepar belum berfungsi secara maksimal, sehingga proses glukuronidasi bilirubin tidak terjadi secara maksimal. Keadaan ini akan menyebabkan dominasi bilirubin tak terkonjugasi di dalam darah. Pada beberapa bayi, terjadi peningkatan bilirubin secara berlebihan sehingga bilirubin berpotensi menjadi toksik dan dapat menyebabkan kematian dan bila bayi tersebut dapat bertahan hidup pada jangka panjang akan menimbulkan sekuele neurologis. Dengan demikian, setiap bayi yang fisiologis atau patologis serta dimonitor apakah mempunyai kecenderungan untuk berkembang menjadi hyperbilirubinemia yang berat (Kosim S dkk, 2012).

Negin S dkk (2016) mengatakan bahwa kondisi yang patologis yang paling umum terjadi pada neonatus adalah hiperbilirubinemia. Hal ini merupakan salah satu tanda terjadinya kerusakan pada sistem saraf pusat. Berbagai kerusakan neurologis dapat terjadi oleh hiperbilirubinemia dan sangat tergantung paparan akut atau kronis bilirubin tersebut terhadap sistem saraf pusat. Salah satu organ yang sangat sensitif terhadap kadar bilirubin yang tinggi adalah sistem pendengaran. Oleh karena itu penting untuk mendiagnosis secara dini gangguan pendengaran oleh karena kadar bilirubin yang tinggi.

Menurut Bolajoko dkk (2015), sekitar 60\%-80\% bayi baru lahir di seluruh dunia mengalami ikterus neonatal (hiperbilirubinemia) dalam kondisi yang tidak dapat disembuhkan. Meskipun beberapa kasus dapat tertolong, namun mengalami perkembangan sistem saraf yang lambat, seperti cerebral palsy, gangguan sensorineural pendengaran, serta kesulitan perkembangan intelektual yang lambat.

Sana U (2016) juga melaporkan bahwa hiperbilubinemia adalah gangguan yang mengancam jiwa pada bayi baru lahir karena terkait dengan gangguan multifaktorial.Hiperbilubinemia

merupakan penyakit yang mudah didiagnosis, namun membutuhkan penanganan yang cepat dan tepat, karena dapat menimbulkan banyak komplikasi, diantaranya gangguan perkembangan sistem saraf pusat, termasuk gangguan perkembangan neurologis.

\section{Hubungan antara kematian BBLR dengan hipotermia}

Tabel 5.

Distribusi Bayi Berat Lahir Rendah

(BBLR) yang Meninggal dan Mengalami

Hipotermi di RSUD Labuang Baji

Tahun 2013-2015 


\begin{tabular}{|c|c|c|c|c|c|c|c|}
\hline \multirow{2}{*}{ BBLR } & \multicolumn{2}{|c|}{ Hidup } & \multicolumn{4}{|c|}{ Meninggal Jumlah } & \multirow{2}{*}{$\begin{array}{c}P \\
\text { value }\end{array}$} \\
\hline & $\mathbf{N}$ & $\%$ & $\mathbf{n}$ & $\%$ & $\mathbf{N}$ & $\%$ & \\
\hline Hipotermi & 12 & 13,5 & 72 & 61 & 84 & 40 & \\
\hline Tidak hipotermi & 77 & 86,5 & 46 & 39 & 123 & 59 & $4_{0,000}$ \\
\hline
\end{tabular}

$\begin{array}{llllllll}\text { Jumlah } & 89 & 100 & 118 & 100 & 207 & 100\end{array}$

Sumber : Data primer

Tabel 5. menunjukkan bahwa dari 89 BBLR yang hidup, 13,5\% mengalami hipotermi dan 86,5\% tidak mengalami hipotermi. Sedangkan BBLR yang meninggal, $61 \%$ mengalami hipotermi dan $39 \%$ tidak mengalami hipotermi.Hasil analisis chi-square didapatkan nilai $\mathrm{p}=$ 0,000 (signifikan), nilai ini berarti ada pengaruh hipotermi terhadap kematian BBLR.

Hipotermia merupakan kondisi yang dapat dicegah dan sangat mempengaruhi morbiditas dan mortalitas, khususnya pada bayi prematur. Pemeliharaan suhu badan normal harus diprioritaskan, baik pada bayi sakit maupun sehat. Untuk bayi sehat dapat dilakukan dengan menggunakan selimut hangat, menjauhkan kain basah, meletakkan anak di dasa ibu (skin to skin contact), menggunakan topi dan pakaian. Pada bayi sakit biasanya bayi tidak menggunakan pakaian dan diletakkan di atas radiant warmer untuk memudahkan observasi dan tindakan. Selama resusitas dan stabilisasi, juga meningkatkan risiko terjadinya stress dingin dan hipotermia.

Pada bayi prematur dan berat badan lahir rendah sangat rentan mengalami hipotermia. Hal ini terjadi karena bayi masih memiliki kesulitan dalam mengatur keseimbangan antara produksi dan kehilangan panas, terutama bayi kecil masa kehamilan. Hal ini disebabkam karena perbandingan antara luas permukaan dan massa tubuh yang lebih besar, kulit imatur yang lebih tipis, dan lemak coklat yang lebih sedikit (Effendi SH, Puspitasari M, 2012).

Menurut (Hutagaol SH dkk, 2014) Bayi baru lahir kehilangan panas 4 kali lebih besar dari pada orang dewasa, sehingga mengakibatkan terjadinya penurunan suhu. Pada 30 menit pertama, abyi dapat mengalami penurunan suhu 3$4^{\circ} \mathrm{C}$. Pada ruangan dengan suhu $20-25^{\circ} \mathrm{C}$ suhu kulit bayi turun sekitar $0,30^{\circ} \mathrm{C}$ permenit. Penurunan suhu diakibatkan oleh kehilangan panas secara konduksi, konveksi, evaporasi dan radiasi. Kemampuan bayi belum sempurna dalam memproduksi panas, maka bayi rentan untuk mengalami hipotermia.

Menurut Procianoy RS, Silveiraa RC (2015), bayi dengan hipotermi jika diberi terapi maka secara signifikan akan mengurani kesakitan dan kematian bayi yang dilahirkan dengan asfiksia perinatal. Akan tetapi beberapa yang masih bertahan hidup namun dengan sequele sehingga dibutuhkan rawat jalan.

\section{Hubungan antara Kematian BBLR dengan Respiratory Distress Syndrom (RDS)}

Tabel 6.

Distribusi BBLR yang Meninggal dan Mengalami Respiratory Distress Sydrom (RDS) di RSUD Labuang Baji Tahun 2013-2015

\begin{tabular}{cccccccc}
\hline \multirow{2}{*}{ BBLR } & \multicolumn{6}{c}{ Hidup } & \multicolumn{3}{c}{ Meninggal Jumlah } & $\boldsymbol{P}$ \\
& $\mathbf{N}$ & $\boldsymbol{\%}$ & $\mathbf{n}$ & $\boldsymbol{\%}$ & $\mathbf{N}$ & $\mathbf{\%}$ & value \\
\hline RDS & 17 & 19,1 & 66 & 55,9 & 83 & 40,1 \\
Tidak RDS & 72 & 80,9 & 52 & 44,1 & 124 & 59,9 & 0,000 \\
\hline Jumlah & $\mathbf{8 9}$ & $\mathbf{1 0 0}$ & $\mathbf{1 1 8}$ & $\mathbf{1 0 0}$ & $\mathbf{2 0 7}$ & $\mathbf{1 0 0}$ \\
\hline
\end{tabular}

Sumber : Data primer

Tabel 6. menunjukkan bahwa dari 89 BBLR yang hidup, 19,1\% mengalami RDS dan $80,9 \%$ tidak mengalami RDS. 
Sedangkan BBLR yang meninggal, 55,9\% mengalami RDS dan $44,1 \%$ tidak mengalami RDS.Hasil analisis chi-square didapatkan nilai $\mathrm{p}=0,000$ (signifikan), nilai ini berarti ada hubunganRespiratory Distress Sydrom (RDS) terhadap kematian BBLR.

Menurut Edwards MO dkk (2013), distress pernafasan sering terjadi pada periode neonatal awal (bayi baru lahir). Sebahagian besar terjadi RDS dan penyakit paru kronis pada bayi prematur ( $<37$ minggu masa kehamilan) dan risiko tersebut menurun pada bayi dengan masa kehamilan > 37 minggu. Sangat dibutuhkan upaya deteksi secara dini dan inisiasi pengobatan yang tepat penting dilakukan untuk menghasilkan hasil yang optimal.

Penelitian yang dilakukan oleh Betoon ML dkk (2011) bahwa dari 192 subyek penelitian yang dikumpulkan terdiri dari 61 bayi dengan masa kehamilan cukup bulan ( $\geq 37$ minggu), 131 bayi dengan masa kehamilan kurang bulan $(<34$ minggu), 88 orang $(67,17 \%)$ diantaranya yang mengalami syndrom gangguan nafas, 35 orang $(26,71 \%)$ yang berkembang menjadi infeksi paru kronis dan 8 orang $(6,10 \%)$ yang berakhir dengan kematian.

Distress pernafasan atau gangguan nafas merupakan masalah yang sering dijumpai pada hari-hari pertama kehidupan BBL, ditandai dangan takipnea, nafas cuping hidung, retraksi interkostal, sianosis dan apnu. Salah satu gangguan nafas paling sering ialah Respiratory Distress Syndrom (RDS) yang dikenal juga dengan sitilah Sindrom Gangguan Nafas (SGN) atau penyakit membran hialin. Keadaan ini, hampir terjadi sebagian besar pada Bayi Kurang Bulan (BKB). Insiden dan derajat penyakit ini berhubungan erat dengan umur kehamilan. Pemberian surfaktan secara dini utnuk kasus defisiensi surfaktan dan teknik penggunaan ventilator (Kosim S dkk, 2012).

\section{Simpulan}

1. Ada hubungan yang signifikan antara asfiksia terhadap kejadian kematian BBLR.

2. Ada hubungan yang signifikan antara infeksi/sepsis terhadap kejadian kematian BBLR.

3. Ada hubungan yang signifikan antara hipoglikemia terhadap kejadian kematian BBLR.

4. Ada hubungan yang signifikan antara hiperbilirubinemia terhadap kejadian kematian BBLR.

5. Ada hubungan yang signifikan antara hipotermia terhadap kejadian kematian BBLR.

6. Ada hubungan yang signifikan antara Respiratory Distress Syndrom (RDS) terhadap kejadian kematian BBLR.

\section{Saran}

1. Perlunya upaya deteksi dini komplikasi yang mungkin terjadi pada bayi dengan BBLR

2. Perlunya penanganan yang tepat dan cepat, termasuk sistem rujukan bayi dengan BBLR.

\section{DAFTAR PUSTAKA}

Agustin Conde-Agudelo; Anyeli RosasBermúdez; Ana Cecilia KafuryGoeta, 2006, Birth Spacing and Risk of Adverse Perinatal Outcomes: A Meta-Analysis. Vol 295, No.15, JAMA;295(15):1809-1823.

Ali B, Sinan U, 2016, Neonatal Hypoglycemia, The Medical Bulletin of Şişli Etfal Hospital, Volume: 50, Number 1, 2016. file://C:/Users/user/Downloads/961456128417.pdf

Altman M, Vanpe' e M, Cnattingius S, Norman M, 2011, Neonatal Morbidity in Moderately Preterm 
Infants: A Swedish National Population-Based Study; the Journal of Pediatrics Vol. 158, No. 2, hal: 239.
Beeton ML, Maxwell
NC, Davies
PL, Nuttall
D, McGreal
E, Chakraborty
M, Spiller
OB, Kotecha S, 2011, Role of pulmonary infection in the development of chronic lung disease of prematurity, European Respiratory, Journal, Volume 37:6, http://erj.ersjournals.com/content/erj /37/6/1424.full.pdf.

Behrman, Kleigman, Arvin, editor edisi bahasa Indonesia Wahab SA, 2000, Ilmu Kesehatan Anak, Nelson. Edisi 15 Vol.1, EGC,Jakarta.

Bolajoko O.O, Folasade BO, Tina MS, 2015, Risk Factors for Severe Neonatal Hyperbilirubinemia in Low and MiddleIncome Countries: A Systematic Review and MetaAnalysis, PLOS ONE DOI:10.1371/journal.https://www.n cbi.nlm.nih.gov/pmc/articles/PMC4 326461/pdf/pone.0117229.pdf.

Christoph PH, Prem F, Reese HC, Kevin W, Daniel KB, Brian S, and Michael C, 2012, Early and Late Onset Sepsis in Very-Low-Birth-Weight Infants from a Large Group of Neonatal Intensive Care Units, Early Hum Dev. 2012 May ; 88(Suppl 2): https://www.Ncbi.nlm. nih.gov/pmc/articles/PMC3513766/ pdf/nihms424054.pdf.

Cunningham FG, Gant NF, Leveno KJ, Gilstraf LC, Hauth JC, Wenstom KD, 2006, William Obstetri, Vol.1, edisi 21, EGC,Jakarta.

Cunningham G, Leveno KJ, Bloom SL, Hauth JC, Rouse DJ, Spong CY,
2010, William's Obstetrics $23^{\text {rd }}$ edition. The McgrawHillcompanies.

Department of Reproductive Health and Research, 2003, Managingnewborn problems: a guide for doctors, nurses, and midwives. Geneva: WHO Library cataloguing-inpublication data.

Department of Reproductive Health and Research. Kangaroo mother care, 2003, a practical guide. Geneva: WHO Library cataloguing-inpublication data.

Depkes RI, 2008, Perawatan Bayi Berat Lahir Rendah (BBLR) dengan Metode Kanguru: Health Technology Assesment Indonesia; Jakarta.

Deshpande Jayant D, Phalke DB, Bangal VB, D Peeyuusha, Bhatt Sushen, 2011, Maternal risk factor for low birth weight neonates: a hospital based case-control study in rural area of western Maharashtra, India.; National Journal of Community Medicine Vol 2 Issue3.

Edwards MO, Kotecha S, Kotecha SJ, , 2013, Respiratory Distress of the Term Newborn Infant, Paediatric Respiratory Reviews. http://www. prrjournal.com/article/S1526-0542 (12)00007-3/pdf.

Effendi SH, Puspitasari M, 2012, Stabilisasi Neonatus Pasca Tindakan Resusitasi Bayi. http://pustaka. unpad.ac.id.

Emma GD, Margot JT,, 2013, Brain Development in Infants Born Preterm: Looking Beyond Injury, Elsevier, Volume 20, Issue 2, June 2013. http://www.sciencedirect.com /science/article/pii/S1071909113000 
338.

Hafiz MA, Shafaq S, Rafia A, Umair, Sehrish MS, Muhammad WAS, Nazish S, 2014, "Risk factors of birth asphyxia", Aslam et al. Italian Journal of Pediatrics. Italian Journal of Pediatrics. https://www.ncbi. nlm.nih.gov/pmc/articles/PMC4300 075/pdf/13052_2014_Article_94.pdf Hanretty KP, 2003, Obstetrics illustrated. Sixth edition. Glasgow; Elsevier Livingstone.

Hutagaol SH, Darwin E, Yantri E, 2014, Pengaruh Inisiasi Dini (IMD) terhadap suhu dan Kehilangan Panas pada Bayi Baru Lahir, http://jurnal.fk.unand.ac.id

Kemenkes RI, 2010, Riset Kesehatan Dasar, Badan Penelitian dan Pengembangan kesehatan. Kemenkes RI : Jakarta.

Kemenkes RI, 2011, Manajemen Bayi Berat Lahir Rendah (BBLR) untuk Bidan di Desa, Direktorat Jenderal Bina Gizi dan Kesehatan Ibu dan Anak Kementerian Kesehatan RI, Jakarta.

Kemenkes RI, 2014, Pedoman Pelayanan Kesehatan Reproduksi Terpadu di Tingkat Pelayanan Kesehatan Dasar,Jakarta.

Khashu M, Narayanan M, Bhargava S, Osiovich H, 2009, Perinatal outcomes associated with preterm birth at 33 to 36 weeks' gestation: a population- based cohort study; british columbia, canada; American Academy of Pediatrics.

Kosim S, Yunanto, Dewi R, Sarosa GI, Usman A, Neonatologi, Ikatan Dokter Anak Indonesia, Cetakan ketiga,2012.

Mathias K, Elisa MS, Rashmi M, Andreas
S, Andreas WF, 2013, Very low birth weight preterm infants are at risk for hypoglycemia once on total enteral nutrition, the Journal of Maternal Fetal \& Neonatal Medicine, vol 26, 2013, http://www.tandfonline.com/doi/full $/ 10.3109 / 14767058.2013 .784250$ ?sc roll=top\&needAccess $=$ true

Negin S, Fereshte B, Hamid RF, 2016, Effects of Hyperbilirubinemia on Auditory Brainstem Response of Neonates Treated with Phototherapy, Iranian Journal of Otorhinolaryngology, Vol. 28 (1), Serial No.84, Jan 2016. https://www.ncbi.nlm.nih.gov/pmc/a rticles/PMC4735613/pdf/ijo-28023.pdf

Ogunlesi, T.A., 2011, Factors influencing the survival of newborn babies weighing $<1.5 \mathrm{~kg}$ in Sagamu, Nigeria. Archives of Gynecology and Obstetrics,284(6), pp.1351-7. http:www.ncbi.nlm.nih.gov/pubmed

Onesmus MM, Elizabeth E, Anselimo M, 2015, Factors associated with low birth weight among neonates born at Olkalou District Hospital, Central Region, Kenya, Pan African Medical Journal - ISSN: 19378688.https://www.ncbi.nlm.nih.gov/ pmc/articles/PMC4458305/pdf/PA MJ-20-108.pdf.

Procianoy RS, Silveiraa RC, 2015, Hypothermia therapy for newborns with hypoxic ischemic encephalopathy,J Pediatr (Rio J). 2015;91(6 Suppl 1):S78---S83.

Ravi Kumar Bhaskar, Krishna Kumar Deo, Uttam Neupane, Subhadra Chaudhary Bhaskar, Birendra Kumar Yadav, Hanoon P. Pokharel, 
and Paras Kumar Pokharel. A Case Control Study on Risk Factors Associated with Low Birth Weight Babies in Eastern Nepal, International Journal of Pediatrics, 2015.http://dx.doi.org/10.1155/2015 /807373.

Saifuddin AB, 2009, Buku Acuan Nasional Pelayanan Kesehatan Maternal dan Neonatal, BPSP,Jakarta.

Sana U, Khaista R ,2016, Mehdi H, Hyperbilirubinemia in Neonates: Types, Causes, Clinical Examinations, Preventive Measures and Treatments: A Narrative Review Article, Iran J Public Health, Vol. 45, No.5, May 2016. https://www.ncbi.nlm.nih.gov/pmc/a
rticles/PMC4935699/pdf/IJPH-45558.pdf.

Seyyen AA,Mohammad KS,Seyyed ARF, Farideh S,Ahmad RS,Fatemeh E, 2016, Antibiotic Therapy for Very Low Birth Weigh Newborns in NICU,Iran J Pediatr. 2016 April; 26(2):e2612, https://www.ncbi.nlm. nih.gov/pmc/articles/PMC4904487/ pdf/ijp-26-02-2612.pdf.

Ve'dı's HE, Tinna LS, Ragnheiður IB, Robert K, Sven C, Unnur AV, 2013, Low Birth Weight, Small for Gestational Age and Preterm Births before and after the Economic Collapse in Iceland: A Population Based Cohort Study, https://dash. harvard.edu/bitstream/handle/1/1187 9257/3851132.pdf?sequence $=1$. 